\title{
Convection heat and mass transfers in a vertical duct
}

\author{
Chesneau X., Pietri L., Bresson J., Zeghmati B.
}

Groupe de Mécanique, Acoustique et Instrumentation - Centre d'Etudes Fondamentales, UPRES EA 2986

Université de Perpignan, 52 avenue de Villeneuve, 66860 Perpignan cedex

\begin{abstract}
Heat and mass transfers are analysed in a vertical duct where an air flow is established. One of the plates is heated and cooled by a falling water film. Temperatures at the wall and at the water-air interface are measured using thermocouples and an infrared thermography system. It is shown that the infrared camera measures the water surface temperature. From temperature measurements, local Nusselt numbers are calculated for different wall heat flux densities and liquid mass rates. From these Sherwood numbers are deduced using Lewis function assumption.
\end{abstract}

\section{Introduction}

Liquid films falling down along a wall are implied in several industrial applications such as condensers or evaporators. They can result from the condensation of vapor mixed within a gas circulating in a duct. Otherwise, they are used to protect walls from high temperature fluid or to cool heated walls. Therefore, they were the subject of many studies $[1,2,3,4]$.

The film properties have a non negligeable influence on the heat and mass transfer intensities as emphasized by Miyara [4]. Free surface shape, film thickness or liquid-vapor interface temperature behaviors have then to be known to quantify correctly the transfers. On the other hand, transfers are also increased by the presence of waves on the film surface [4], the film thickness continuously fluctuating. A large literature deals with wavy liquid films. To resume, heat carried away by a streaming film interacting with an air flow is essentially a function of its thickness and the fluid nature [3].

Although wall temperature measurements are not problematic, temperatures are not easy to obtain at the interface between the liquid film and the gas flow. Optical methods such as the infrared thermography would be preferable to intrusive techniques. Unfortunately, literature examples are relatively scarce. Hetsroni and Rozenblit [5] visualized thermal patterns in a vertical water-air flow by infrared thermography and analysed their behavior relative to the flow regime. They measured the temperature at the interface between the flow and a heated thin constantan foil through which the temperature loss was found negligeable. Saylor et al. [6] developed an infrared technique to obtain the surface temperature field of water during film spreading. They studied temperature fluctuations at the surface of a water tank after a very thin surfactant liquid film deposition and spreading. At last, Daiff et al. [7] examined the evaporation of a liquid film streaming along the heated wall of a rectangular duct. Water surface and wall temperatures, measured respectively by infrared thermography and thermocouples, agreed well with results provided by a numerical model developed by the authors, except at the entry and the exit of the duct. The authors explained the observed differences firstly by the lack of the liquid uniformity at the channel entrance and secondly by pertubations at its end. Few studies focused therefore on the measurement of the interface temperature by infrared thermography.

The aim of this work is to measure the surface temperature between an air flow and a water film falling down along a heated plate by using an infrared camera. Then, owing to infrared measurement of the interfacial temperature, we deduce heat transfer coefficients through the film between the plate and the air flow. Measurements are realized for several heat flux densities, $1600<\Phi_{\mathrm{p}}<8000 \mathrm{~W} / \mathrm{m}^{2}$, liquid mass rates, $0.025<\dot{\mathrm{m}}_{1}<0.07 \mathrm{~kg} / \mathrm{s}$, and for a 
single air flow rate, $0.065 \mathrm{~kg} / \mathrm{s}$. Results are presented as temperature profiles and local Nusselt numbers.

\section{Experimental set-up}

The test section (fig. 1) has a uniform cross-section ( $300 \mathrm{~mm}$ wide, $30 \mathrm{~mm}$ thick). It is $1 \mathrm{~m}$ high. The back streamwise plate is aluminium-made and $8 \mathrm{~mm}$ thick. Six electrical resistances are fixed behind it and provide homogeneous and constant heating of the liquid film. Twenty chromel alumel thermocouples are regularly spaced all along and measure the plate temperatures which are digitalized with an analog/digital card and stored in a computer. A slide along the Plexiglas front plate permits the introduction of probes or the set of an optical infrared window. This optic is ZnSe-made and $3 \mathrm{~mm}$ thick. Its transmittivity is almost equal to the unity for a wavelengths range between $3 \mu \mathrm{m}$ and $14 \mu \mathrm{m}$ and $\mathrm{a} \pm 60 \mathrm{~K}$ temperature interval. It collects consequently the overall infrared radiation emitted by the airwater interface. The air coflow is blown by a centrifugal fan. The liquid mass rate is given by a cylindrical float flowmeter.

At the air-water interface, the temperature is measured by infrared thermography with an Inframetrics model 760 radiometer. A mercury-cadmium-telluride detector is cooled by an integrated cooler to $77 \mathrm{~K}$. It operates in the 3-12 $\mu \mathrm{m}$ waveband, which can be reduced to the range 8-12 $\mu \mathrm{m}$ by an internal filter. In our working spectral band, the thermal resolution (minimum detectable temperature difference) given by the constructor [8] is $0.1 \mathrm{~K}$ at $303 \mathrm{~K}$. The noise equivalent temperature difference, which completes the thermal resolution concept is inferior to $0.2 \mathrm{~K}$. Finally the horizontal resolution is equal to 256 pixels per line and the elementary angle of measurement is $1.8 \mathrm{mrad}$.

The camera is placed in front of a thermocouple, allowing the determination of the heat exchange emitted by the liquid film surface at a given section. The distance between the infrared camera and the plate is kept equal to $15 \mathrm{~cm}$. A videotape records the thermal sequences, which are then processed using the Thermagram software after computer storage.

\section{Validity of the use of an infrared camera to measure the temperature at an air-water interface}

Temperature measurement at the interface between the liquid film and the air flow is based on the hypothesis that the heat flux collected by the infrared camera comes mainly from the liquid surface. This assumption has to be verified before any measurement. A first step was accomplished with the comparison of numerical and experimental surface temperatures [7]. However it is not sufficient to valid the measure. For this purpose, different tests are led.

Without plate heating and with falling liquid film, the plate temperature at the section $x / L=0.65$ is around $286.2 \mathrm{~K}$. The infrared radiometer measurement achieves this value when we assign the value of 0.96 to the emissivity. It is noteworthy that this value is characteristic of water emissivity.

Moreover, we determine the temperature measured by the infrared system at the section $x / L=0.35$ in two cases: without film and with film. We apply to the plate a heat flux density $\Phi_{p}$ of $1600 \mathrm{~W} / \mathrm{m}^{2}$. Without water film, since one of thermocouples provides the plate temperature, we are able to estimate the emissivity of the plate, almost 0.1 , which agrees well with polish aluminium emissivity. This checks our first measurement. As the water transmittivity for depths of some tenths of $\mathrm{mm}$ is quasi null, the heat flux emitted by the plate is almost completely absorbed by the film. With water emissivity, the temperature reaches $284.6 \mathrm{~K}$ that is smaller than the plate temperature of $287.2 \mathrm{~K}$. This slight temperature difference seems well representative of the heat transfer between the plate and the air flow. 
In order to estimate the surface temperature from a theoretical model, the energy balance based on a nodal analysis is written for a fictitious slice of the duct. Entry parameters are known: liquid and air mass rates, temperatures, relative humidity. The plate heat flux is imposed. The film thickness is calculated by solving the transfer equations in the film and expressed as [7]:

$$
\delta^{\mathrm{dl}}=\left[\frac{3 v_{1}^{\mathrm{dl}} \dot{\mathrm{m}}_{1}^{\mathrm{dl}} \mathrm{Fr}}{\rho_{1}^{\mathrm{dl}} \mathrm{Re}_{\mathrm{a}}}\right]^{1 / 3} .
$$

The convection transfers are quantified using classical correlations. The condition at the liquid-air interface is complex because of the interaction between the falling film and the air flow. To take into account its effect, we used the heat transfer coefficient deduced from the Petukhov correlation [9]. Finally, the Plexiglas plate is supposed infinitely thin to neglect conduction inside it. With the additional hypothesis of steady-state, the four equations are solved iteratively. The four unknowns are the interface, air flow, Plexiglas and plate temperatures.

Assigning various values to water emissivity doesn't affect the water-air interface: the heat transfer through the liquid film is mainly due to conduction. The calculated temperature variation between the plate and the film surface agrees relatively well with the experimental results in spite of a few assumptions, which the model is based on. These two last points validate that we measure actually the interface temperature with the infrared camera.

\section{Heat transfer charaterization}

Wall and interfacial temperatures are obtained for different plate heat flux densities $\Phi_{p}$ and different liquid mass rates $\dot{m}_{1}$. For the largest $\dot{m}_{1}$ (fig. 2 ), the slope of the wall temperature profile increases with $\Phi_{\mathrm{p}}$. A slope break-up, more accentuated for the highest flux density $\Phi_{p}=6600 \mathrm{~W} / \mathrm{m}^{2}$, occurs at the section $x / L=0.55$. It could be probably related to a leap of plate heating. The behavior of the interfacial temperature is similar except for the case of the lowest flux density $\Phi_{\mathrm{p}}=1600 \mathrm{~W} / \mathrm{m}^{2}$ : the interfacial temperature remains quasi constant along the plate.

From these measurements, we deduce the local heat transfer coefficient $h_{x}$ and the local Nusselt number $\mathrm{Nu}_{x}$. The transfer coefficient $\mathrm{h}$ is deduced from the Newton's law:

$$
\Phi=h_{.}\left(T_{p}-T_{*}\right) \text {. }
$$

$T$ * refers to $T_{s}$ when we consider the transfer in the liquid film and to $T_{a}$ for the transfer between the air flow and the plate. The error related to temperature measurements, taking into account inaccuracies of the heat flux density and the plate dimensions, is estimated inferior to $10 \%$. The physical properties are evaluated for the average temperature $\mathrm{T}_{\mathrm{av}}=$ $\left(T_{p}+T_{a}\right) / 2$.

The local Nusselt number $\mathrm{Nu}_{\mathrm{x}}$ is determined as relative to the streamwise position (fig. 3). For the heat flux density $\Phi_{p}=8300 \mathrm{~W} / \mathrm{m}^{2}$, the temperature difference $T_{p}-T_{s}$ decreases strongly with $x / L$ while it doesn't vary too much for the other fluxes. Then the Nusselt number grows more quickly. The heat transfer between the plate and the film is enlarged because the vaporization process decreases, and so the latent heat transfer between the film and the air flow. Indeed the gas flow is more and more saturated with vapor far from the entry. If we consider now the Nusselt number characteristic of the heat transfer between the plate and the air flow, its evolution is smoother and a sort of level appears from $x / L=0.5$ : some heat transfer balance is reached between the plate and the air flow. For wall flux densities inferior to $8000 \mathrm{~W} / \mathrm{m}^{2}$, the heat transfer stabilizes in the liquid film while it increases continuously between the gas and the plate due to water evaporation.

For the wall heat flux density $\Phi_{p}=1600 \mathrm{~W} / \mathrm{m}^{2}$ (fig. 4), the local Nusselt number representative of the heat transfer between the plate and the gas is evaluated for three liquid mass rates. From the entry of the duct to $x / L=0.5$, the transfers are almost equivalent. But 
further in the channel, smaller is the liquid mass rate, larger the Nusselt number because of an enhanced water evaporation. The local Nusselt numbers are interpolated by the least squares method. The following correlation is obtained:

$$
\mathrm{Nu}_{\mathrm{x}}=32.4\left(\frac{\mathrm{x}}{\mathrm{L}}\right)^{0.112} \mathrm{Re}_{\mid}^{-1} \mathrm{Gr}_{\mathrm{x}}^{0.55} ; 3.10^{12} \leq \mathrm{Gr}_{\mathrm{x}} \leq 2.10^{13}
$$

Heat transfer coefficients agree well with those determined by Fujita et Ueda [10].

The mass transfer can be quantified using the Lewis function. Indeed the Lewis function is expressed by the following formula:

$$
F(\text { Le })=\frac{h}{h_{M}} \times \frac{1}{\rho C p)_{a}}
$$

where $h_{M}$ is the mass transfer coefficient. A useful hypothesis based on quasi equal Schmidt and Prandtl numbers assumes this function equal to 1 . Since these numbers take very close values for water vapor, the Sherwood number can be simply evaluated. The Sherwood and Nusselt numbers have similar behaviors.

\section{Conclusion}

The objective of this study was to quantify the convective heat and mass transfers occurring between a gas flow and a liquid film falling along an heated plate. First, we verified that the temperature of the air-water interface was measurable with the infrared thermography. For this purpose, the energy balance in the duct was written and solved by using a numerical method. The slight difference between the interfacial and wall temperatures is physically in agreement with the heat transfer processus in the duct.

After this preliminary step, temperature measurements used to evaluate the heat transfer through Nusselt number calculation. When the wall heat flux is increased, the heat transfer in the film increases continuously in the channel because of evaporation diminution. On the other hand, the transfer between the air flow and the plate seems to stabilize from the plate location $x / L=0.5$. If the liquid mass rate grows up, the heat transfer is still limited due to the presence of vapor in the gas impeding the evaporation further in the duct.

Finally, the heat transfer characterization allows us to approximate the mass transfer between the liquid film and the air flow simply with temperature measurements using the hypothesis of unity Lewis function.

\begin{tabular}{|c|c|c|c|}
\hline Cp & thermal capacity & {$[\mathrm{J} /(\mathrm{kg} . \mathrm{K})]$} & Indices \\
\hline e & interplate distance & [m] & a air \\
\hline$g$ & gravity acceleration & {$\left[\mathrm{m} / \mathrm{s}^{2}\right]$} & av average \\
\hline $\mathrm{h}$ & heat transfer coefficient & {$\left[\mathrm{W} /\left(\mathrm{m}^{2} . \mathrm{K}\right)\right]$} & I liquid \\
\hline$h_{M}$ & mass transfer coefficient & {$[\mathrm{m} / \mathrm{s}]$} & $\mathrm{p}$ plate \\
\hline $\mathrm{k}$ & thermal conductivity & {$[\mathrm{W} /(\mathrm{m} . \mathrm{K})]$} & s interface \\
\hline $\mathrm{L}$ & plate length & [m] & 0 duct entry \\
\hline$\dot{\mathrm{m}}$ & mass rate & {$[\mathrm{kg} / \mathrm{s}]$} & Exponants \\
\hline$\dot{\mathrm{M}}_{1}$ & liquid mass rate per unit periphery length & {$[\mathrm{kg} /(\mathrm{m} . \mathrm{s})]$} & dl dimensionless \\
\hline $\mathrm{T}$ & temperature & {$[\mathrm{K}]$} & Dimensionless numbers \\
\hline $\mathrm{u}$ & longitudinal velocity & {$[\mathrm{m} / \mathrm{s}]$} & $\mathrm{Fr} \quad$ Froude number, $\mathrm{u}^{2} /(\mathrm{eg})$ \\
\hline $\mathrm{x}$ & longitudinal coordinate & {$[\mathrm{m}]$} & $\mathrm{Nu}_{\mathrm{x}}$ local Nusselt number \\
\hline$\beta$ & thermal expansion coefficient & {$\left[\mathrm{K}^{-1}\right]$} & $\mathrm{Re}$ Reynolds number, $\mathrm{u}_{0} \mathrm{e} / \mathrm{v}_{0}$ \\
\hline$\delta$ & film thickness & {$[\mathrm{m}]$} & $\mathrm{Re}_{\mid}$liquid Reynolds number, $4 \dot{\mathrm{M}}_{1} / \mu$ \\
\hline $\begin{array}{l}v \\
\rho\end{array}$ & $\begin{array}{l}\text { cinematic viscosity } \\
\text { density }\end{array}$ & $\begin{array}{l}{\left[\mathrm{m}^{2} / \mathrm{s}\right]} \\
{\left[\mathrm{kg} / \mathrm{m}^{3}\right]}\end{array}$ & $\mathrm{Gr}_{\mathrm{X}}$ Grashof number, \\
\hline$\Phi$ & heat flux density & {$\left[\mathrm{W} / \mathrm{m}^{2}\right]$} & $g \beta \Phi_{\mathrm{p}} \mathrm{x}^{3} /\left(\mathrm{k}_{\mathrm{a}} \mathrm{v}_{\mathrm{a}}^{2}\right)$ \\
\hline
\end{tabular}

\section{Nomenclature}




\section{References}

[1] Yan W. M., Lin T. F., 1990, Combined heat and mass transfer in natural convection between vertical parallel plates with film evaporation, Int. J. Heat Mass Transfer, vol. $33, n^{\circ}$ 3, p. 529-541

[2] Fujita T., 1993, Falling films in absorption machines, Int. J. Refrig., vol. 16, n 4, p. $282-$ 294

[3] Ali Cherif A., Daiif A., 1999, Etude numérique du transfert de chaleur et de masse entre deux plaques planes verticales en présence d'un film de liquide binaire ruisselant sur l'une des plaques chauffées, Int. J. Heat Mass Transfer, vol. 42, n 13, p. 2399-2418.

[4] Miyara A., 1999, Numerical analysis on flow dynamics and heat transfer of falling liquid films with interfacial waves, Heat and Mass Transfer, vol. 35, p. 298-306

[5] Hetsroni G., Rozenblit R., 2000, Thermal patterns on a heated wall in vertical air-water flow, Int. Jl Multiphase Flow, vol. 26, p. 147-167

[6] Saylor J. R., Smith G. B., Flack K. A., 2000, Infrared imaging of the surface temperature field of water during film spreading, Phys. Fluids, vol. 12, n 3, p. 597-602

[7] Daïf A., Bresson J., Grisenti M., Ali Chérif A., 1998, Experimental study of liquid film evaporation streaming along one of the walls of a rectangular channel within an air flow, Third Int. Conf. on Multiphase Flow, ICMF'98, Lyon, France, June 8-12, 1998

[8] Inframetrics, 1992, Inframetrics model 760 - IR Imaging radiometer, Operator's manual

[9] An P., Li J., Jackson J. D., 1999, Study of the cooling of a uniformly heated vertical tube by an ascending flow of air and a falling water film, Int. Jl Heat Fluid Flow, vol. 20, p. 268-279

[10] Fujita T., Ueda T., 1978, Heat transfer to falling liquid films and film breakdown - I Subcooled liquid films, Int. Jl Heat Mass Transfer, vol. 21, p. 97-108

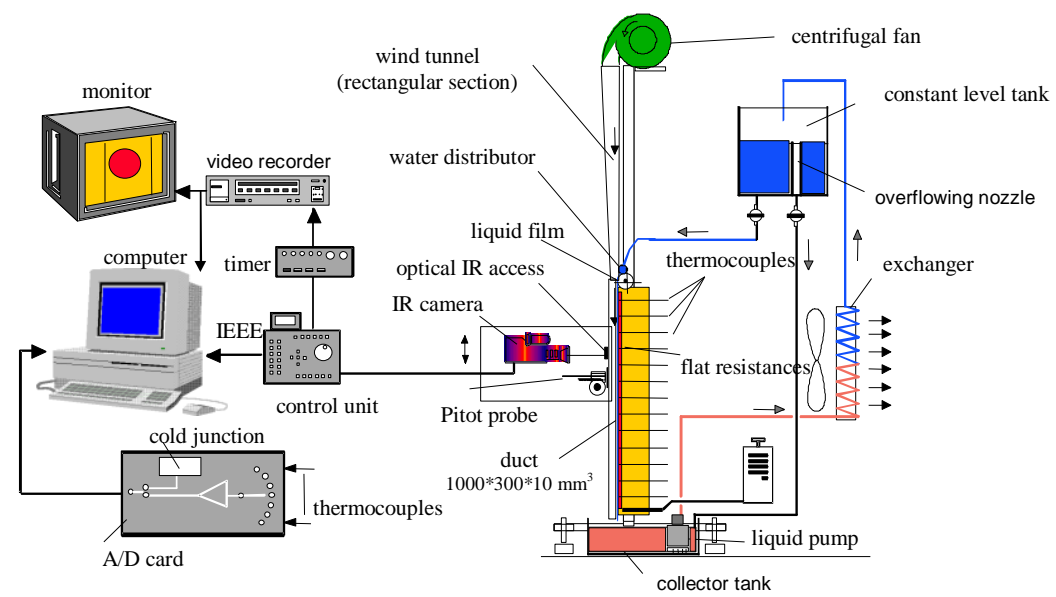

Fig. 1: Experimental set-up 


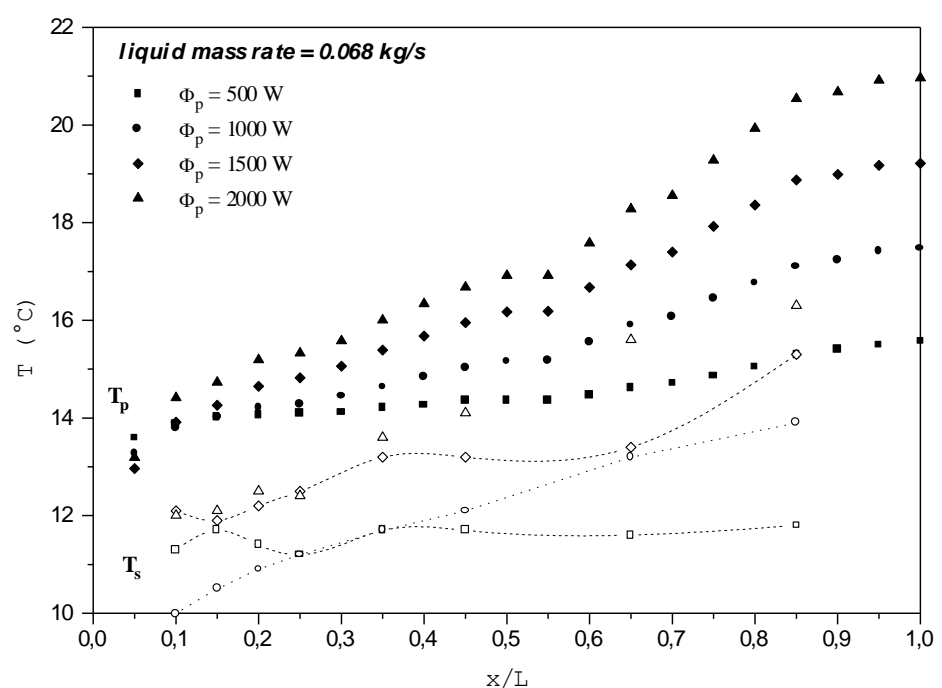

Fig. 2: Evolution of wall temperature $\mathrm{T}_{\mathrm{p}}$ and interface temperature $\mathrm{T}_{\mathrm{s}}$

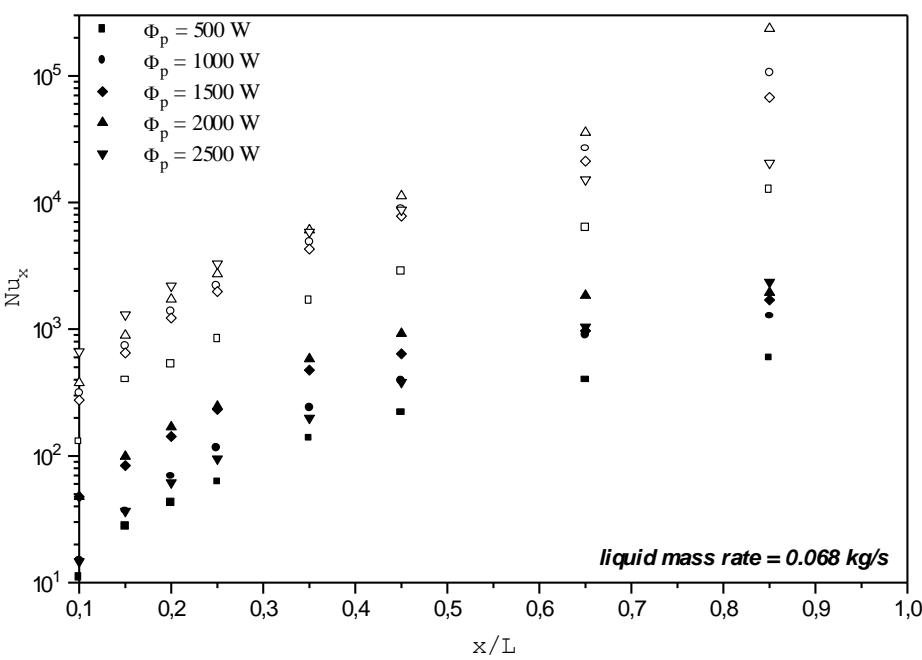

Fig. 3: Evolution of local Nusselt number $\mathrm{Nu}_{\mathrm{x}}-\mathbf{\square}$ : liquid film; $\square$ : air flow

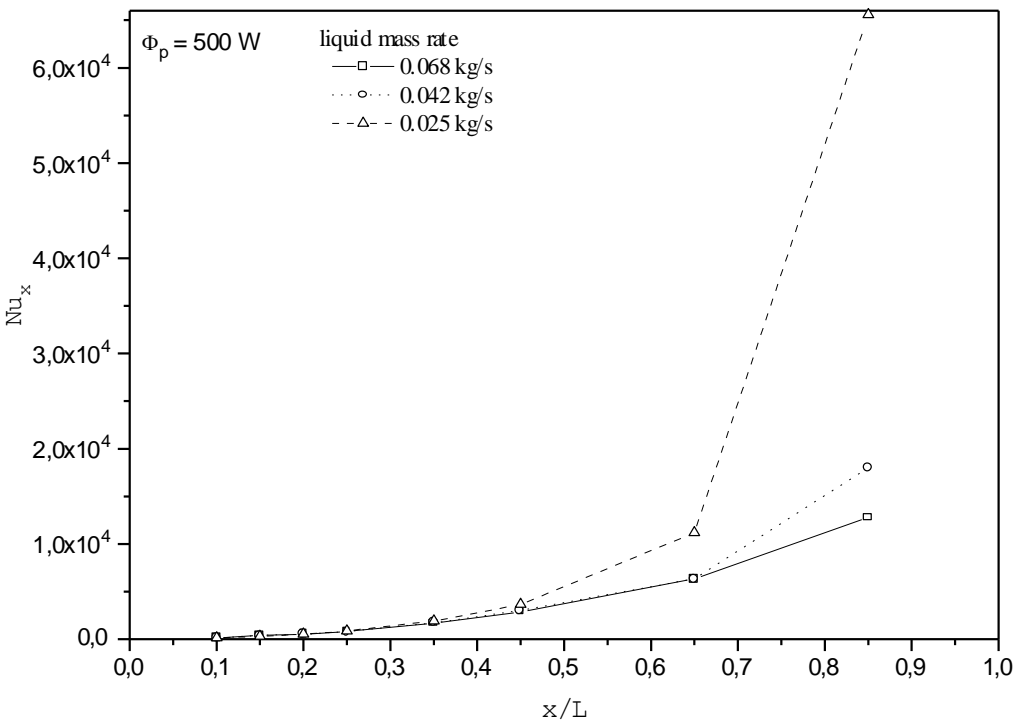

Fig. 4: Local Nusselt number based on the transfer between the wall and the air flow 